\title{
Screening for high hip fracture risk does not impact on falls risk: A post hoc analysis from the SCOOP study
}

Codrin I Condurache ${ }^{1,2}$, Sarah Chiu ${ }^{1,2}$, Pojchong Chotiyarnwong ${ }^{2,3}$, Helena Johansson ${ }^{4,5,6}$, Lee Shepstone ${ }^{7}$, Elizabeth Lenaghan ${ }^{7}$, Cyrus Cooper ${ }^{8,9,10}$, Shane Clarke ${ }^{11}$, Rebekah Fong Soe Khioe ${ }^{7}$, Richard Fordham ${ }^{7}$, Neil Gittoes $^{12}$, Ian Harvey ${ }^{7}$, Nicholas C Harvey ${ }^{8,9}$, Alison Heawood ${ }^{13}$, Richard Holland ${ }^{14}$, Amanda Howe ${ }^{7}$, John A Kanis $^{4,6}$, Tarnya Marshall ${ }^{15}$, Terence W O’Neill ${ }^{16,17}$, Tim J Peters ${ }^{13}$, Niamh M Redmond ${ }^{13,18}$, David Torgerson ${ }^{19}$, David Turner ${ }^{7}$, Eugene McCloskey ${ }^{1,2,4} \&$ the SCOOP Study Team*.

${ }^{1}$ Centre for Integrated research into Musculoskeletal Ageing, University of Sheffield Medical School, Sheffield, UK

${ }^{2}$ Academic Unit of Bone Metabolism, Department of Oncology and Metabolism, The Mellanby Centre For Bone Research, University of Sheffield, Sheffield, UK

${ }^{3}$ Department of Orthopaedic Surgery, Faculty of Medicine, Siriraj Hospital, Mahidol University, Bangkok, Thailand.

${ }^{4}$ Centre for Metabolic Diseases, University of Sheffield Medical School, Beech Hill Road, Sheffield S10 2RX, UK

${ }^{5}$ Centre for Bone and Arthritis Research (CBAR), Sahlgrenska Academy, University of Gothenburg, Gothenburg, Sweden

${ }^{6}$ Mary MacKillop Institute for Health Research, Australian Catholic University, Melbourne, Victoria, Australia. ${ }^{7}$ Norwich Medical School, University of East Anglia, Norwich, UK

${ }^{8}$ MRC Lifecourse Epidemiology Unit, University of Southampton, Southampton, UK;

${ }^{9}$ NIHR Southampton Biomedical Research Centre, University of Southampton and University Hospital

Southampton NHS Foundation Trust, Southampton, UK

${ }^{10}$ Oxford Biomedical Research Unit, University of Oxford, Oxford, UK

${ }^{11}$ Department of Rheumatology, University Hospitals Bristol, Bristol, UK

${ }^{12}$ Centre for Endocrinology, Diabetes and Metabolism, Queen Elizabeth Hospital, Birmingham, UK

${ }^{13}$ Bristol Medical School, University of Bristol, Bristol, UK

${ }^{14}$ Leicester Medical School, Centre for Medicine, University of Leicester, UK

${ }^{15}$ Norfolk and Norwich University Hospital, Norwich, UK

${ }^{16}$ NIHR Manchester Biomedical Research Centre, Manchester University NHS Foundation Trust,

Manchester Academic Health Science Centre, Manchester, UK

${ }^{17}$ Centre for Epidemiology Versus Arthritis, University of Manchester, Manchester, UK

${ }^{18}$ National Institute for Health Research Collaborations for Leadership in Applied Health Research and Care

West (NIHR CLAHRC West), University Hospitals Bristol NHS Foundation, Bristol UK

${ }^{19}$ Department of Health Sciences, University of York, York, UK

* Other SCOOP Study Team members:

Birmingham: Nicola Crabtree, Helen Duffy, Jim Parle, Farzana Rashid, Katie Stant. Bristol: Kate Taylor, Clare Thomas (née Emmett). Manchester: Emma Knox, Cherry Tenneson, Helen Williams. Norwich: David Adams, Veronica Bion, Jeanette Blacklock, Tony Dyer. Sheffield: Selina Bratherton (née Simpson), Matt Fidler,

Katharine Knight, Carol McGurk, Katie Smith, Stacey Young. Southampton: Karen Collins, Janet Cushnaghan. York: Catherine Arundel, Kerry Bell, Laura Clark, Sue Collins, Sarah Gardner, Natasha Mitchell.

Correspondence

Prof. Eugene McCloskey

Email: e.v.mccloskey@sheffield.ac.uk

Telephone: +44 (0)114 2159694

Fax: +44 (0)114 2618775 


\section{ABSTRACT (246 of 250 words allowed)}

Purpose: To investigate whether effectiveness of an osteoporosis screening programme to reduce hip fractures was mediated by modification of falls risk in the screening arm.

Methods: The SCOOP study recruited 12,483 women aged 70-85 years, individually randomised to a control $(\mathrm{n}=6,250)$ or screening $(\mathrm{n}=6,233) \mathrm{arm}$; in the latter, osteoporosis treatment was recommended to women at high risk of hip fracture, while the control arm received usual care. Falls were captured by self-reported questionnaire. We determined the influence of baseline risk factors on future falls, and then examined for differences in falls risk between the randomisation groups, particularly in those at high fracture risk.

Result: Women sustaining one or more falls were slightly older at baseline than those remaining falls free during follow up (mean difference 0.70 years, 95\%CI 0.55-0.85, $\mathrm{p}<0.001$ ). A higher FRAX 10-year probability of hip fracture was associated with increased likelihood of falling, with fall risk increasing by $1-2 \%$ for every $1 \%$ increase in hip fracture probability. However, falls risk factors were well balanced between the study arms and, importantly, there was no evidence of a difference in falls occurrence. In particular, there was no evidence of interaction $(\mathrm{p}=0.18)$ between baseline FRAX hip fracture probabilities and falls risk in the two arms, consistent with no impact of screening on falls in women informed to be at high risk of hip fracture.

Conclusion: Effectiveness of screening for high FRAX hip fracture probability to reduce hip fracture risk was not mediated by a reduction in falls.

KEYWORDS: FRAX, SCREENING, FALLS, FRACTURES, OSTEOPOROSIS, OLDER WOMEN

Conflict of Interest

The authors declare that there is no conflict of interest regarding the publication of this article.

\section{ACKNOWLEDGEMENT}

This study was jointly funded by Versus Arthritis (formerly Arthritis Research UK) and the UK Medical Research Council. NMR's time is supported by the National Institute for Health Research Collaboration for Leadership in Applied Health Research and Care West (NIHR CLAHRC West) at University Hospitals Bristol NHS Foundation Trust. The SCOOP study was designed and done with substantial input from the Norwich Clinical Trials Unit, UK, particularly the construction of the study database and provision of online randomisation (completed by Tony Dyer). We thank Margaret McWilliams and Ann Pulford, the study's public and patient involvement representatives, for invaluable advice and support, and our trial steering committee and data monitoring committee. We also thank Ms. Wachirapan Narktang of the Division of Research, Department of Orthopaedic Surgery, Faculty of Medicine Siriraj Hospital for her assistance with artwork and illustration of the figure. 


\section{Mini abstract (45 of 50 words allowed)}

A reduction in hip fracture incidence following population screening might reflect the effectiveness of anti-osteoporosis therapy, behaviour change to reduce falls, or both. This post hoc analysis demonstrates that identifying high hip fracture risk by FRAX was not associated with any alteration in falls risk. 


\section{INTRODUCTION}

In 2010, in the EU, there were 610,000 hip fractures with their management alone accounting for $€ 25 \mathrm{bn}$ of expenditure [1]. Of many factors that influence the risk of hip fracture, age-related reductions in bone mass and increased likelihood of falling are long recognised to be important contributors [2]. While assessment of falls risk and appropriate interventions aimed at reducing falls risk have been shown to be effective [3], at least in the short term, their impact on the risk of hip fracture is less certain. For example, in a recent review undertaken for the US Preventive Services Task Force, multifactorial interventions or single exercise-based interventions were found to reduce falls risk, but the impact on fractures was not significant [4]. In contrast, several randomised, placebocontrolled trials have shown that treatments directed at preventing bone loss and/or improving bone mass can reduce the incidence of hip fracture by $30-45 \%$ [5-7].

Recently, the UK based SCOOP study investigated whether community-based screening, using a FRAX assessment of 10-year hip fracture probability, could reduce the incidence of fractures by targeting osteoporosis treatment to women at high risk of hip fracture [8]. This large study with 5 years of follow up found that the screening programme led to a $28 \%$ reduction in hip fractures. A subsequent analysis confirmed that the risk reduction was predominantly observed in those deemed to be at high risk of fractures $[8,9]$, suggesting the effect was mediated by appropriately targeted osteoporosis medication. An alternative hypothesis might be that screening itself, and/or the knowledge of being at high risk, coupled with the patient's perception of linkage between falls and fractures, could have altered behaviour related to falls risk. Evidence exists that screening can encourage those screened to improve their health behaviour [10], and that screening participants are more likely to follow health-related feedback and alter their lifestyle than those who do not participate $[11,12]$. In contrast, screening can have a 'certificate of health' effect whereby a negative screening result gives patients reassurance which makes them more resistant to health recommendations in the future as they believe that their current lifestyle is adequate and have a lower perceived threat of disease [10, 11, 13].

Given these potential impacts of screening on lifestyle factors, there is uncertainty as to whether screening for osteoporosis might influence falls occurrence or behaviour. This post hoc analysis of the SCOOP trial aimed to answer this by identifying risk factors for falling, comparing their distribution in the screening and control arms and, finally determining whether falls were reduced in the screening arm, particularly in women informed to be at higher risk of hip fracture and targeted for anti-osteoporosis medications. 


\section{METHODS}

The SCOOP study, a 5-year randomised controlled trial of the impact of screening for high hip fracture risk on fracture incidence, has been described in detail elsewhere $[8,14]$. Briefly, it recruited 12,483 women aged between 70-85 years, untreated for osteoporosis, from 100 GP practices in 7 regions across England.

Baseline data and randomisation

At study entry, clinical risk factors were collected directly from participants by postal questionnaire to assess fracture probability by FRAX. Variables included age, height and weight (to calculate BMI), as well as prior fracture (since the age of 50 years), parental hip fracture, glucocorticoid use, rheumatoid arthritis, smoking and alcohol exposure. Self-reported causes of secondary osteoporosis, including insulin dependent diabetes, Crohn's disease, thyroid overactivity, early menopause, organ transplantation and poor mobility were collected, as well as the number of self-reported falls in the previous 12 months [14]. Participants were then randomised into the two arms of the study, the screening arm or 'usual care' control arm.

Screening and control arms

In the screening arm, the FRAX tool was used to calculate participants' 10-year probability of hip fracture, with those deemed at moderate to high risk of hip fracture invited for a dual-energy x-ray absorptiometry (DXA) measurement of femoral neck bone mineral density (BMD); the 10-year hip fracture probability was then recalculated with inclusion of BMD. The final risk category (low or high) was communicated to the participant and family doctor with those at high risk advised to discuss treatment options. Whether at low or high risk, the GP was also asked to advise about the need to increase exposure to weightbearing exercise, to stop smoking and to decrease alcohol intake, where appropriate. In the control arm, apart from communications to the GP and participant about their inclusion in the study, they received usual care from their GP and did not receive information about fracture risk.

Prior falls and incident falls

Falls in the previous 12 months were captured at study entry and self-reports of subsequent falls were captured by postal questionnaire at $6,12,24,36,48$ and 60 months post randomisation, where patients reported falls occurring since the previous questionnaire completion. Prior or subsequent reported falls were not validated from other independent sources during follow up. A fall was defined as a sudden, unintentional coming to rest on the ground, floor, or other lower level [15].

\section{Statistical analysis}

Differences in baseline characteristics, including clinical risks for FRAX calculation, between those women with or without a fall in the year prior to entry were compared using relevant descriptive statistics.

The proportion of women remaining fall-free was estimated with the Kaplan-Meier method.[16] Cox regression was used to examine the relationships between incident falls and baseline risk factors as well as the assigned study arm, with and without adjustment for predictors of falls. Any participant self-reporting one or more falls during follow-up was classified as a faller. Sensitivity analyses using faller definitions of those experiencing at least 5 falls (i.e. on average 1 or more falls per year during the 5 years of the study) and those experiencing at least 10 falls (i.e. on average 2 or more falls per year during the 5 years of the study) were also conducted.

An extension of Poisson regression model was used to study the relationship between age, the time since baseline, study arm (screening or usual care), and FRAX 10-year probability of hip fracture on the one hand and on the other hand, the time to first fall for base case, and time to $5^{\text {th }}$ or $10^{\text {th }}$ fall for sensitivity analyses. As BMD measurements were not undertaken in all participants, the baseline 10-year FRAX probabilities, 
without the inclusion of BMD, were utilised for these analyses. The variable "10-year probability screening" tested for an interaction between screening effectiveness and baseline 10-year probability, handled as a continuous variable. No reduction in falls risk and a lack of interaction, with a flat relationship across the range of baseline risk, would suggest that screening had no impact on falls risk to mediate the observed reduction in hip fractures. A similar approach was used to investigate an interaction between hip fracture probability and reduced fracture risk in the screening arm compared to the control arm [9].

All analyses were conducted on an intention-to-treat basis with participants analysed according to the group to which they were randomised, irrespective of whether screening was completed. Hazard ratios (HR) for screening effect and $95 \%$ confidence intervals $(95 \% \mathrm{CI})$ were computed for risk of falls as a continuous variable. For presentation, hazard ratios are shown at the 10th, 25th, 50th, 75th, and 90th percentile of fracture probability. 


\section{RESULTS}

Baseline Characteristics

The baseline characteristics of the participants in each study arm are shown in Table 1. There were no appreciable differences between the two arms of the study; importantly, the prevalence of falls in the year prior to study entry was very similar in both arms whether this was analysed as any reported fall or a history of 2 or more falls (i.e. multiple previous falls) (Table 1). Within the screening arm, the prevalence of multiple previous falls was slightly but not significantly higher (14.9\%) in those identified at high future risk of hip fracture by FRAX probability than in the rest of the screening group $(13.1 \%, \mathrm{p}=0.16)$.

Women with a history of one or more falls in the previous year were slightly older, with a higher mean BMI, and higher prevalence of FRAX risk factors apart from smoking (Table 2).

Incident falls

During the follow-up period providing 59,401 person-years of observation (mean 4.75 years per participant), there were 24,540 incident falls reported, with 6,760 (54.2\%) of women reporting at least one fall. The proportion of women sustaining a new fall was similar in the control arm (3,332 of 6,250, 53.3\%) and the screening arm $(3,428$ of $6,233,55.0 \%)$. Within those reporting incident falls, the total number of falls reported in any individual ranged from 1 to 314 , with the majority $(4,743,70.2 \%)$ reporting 3 falls or fewer (Table 3).

Those women who sustained one or more incident falls were slightly older at baseline (mean 75.8 years) than those remaining fall free during follow up (mean 75.1 years) (mean difference 0.70 years, 95\%CI 0.55-0.85, $\mathrm{p}<0.001)$. A number of other baseline characteristics were associated with the incidence of subsequent falls, largely independent of the number of incident falls used to classify an individual as a faller or not (Table 4). Thus, a higher BMI, a history of prior fracture, glucocorticoid use, secondary osteoporosis, and fall or the number of falls in the year prior to entry were consistently associated with an increased risk of falling across the different classifications of fallers. In addition, a higher FRAX 10-year probability of hip fracture was also consistently associated with higher subsequent risk of falling with fall risk increasing by $1-2 \%$ for every $1 \%$ increase in hip fracture probability (Table 4). Importantly, there was no evidence that assignment to the screening arm had an impact on the future incidence of falls (Table 4 and Fig 1). Fall-free survival, whether this was defined as free from any fall (Fig 1a) or, at the other extreme, free from at least 10 falls (Fig 1b) was very similar in the screening and control arms.

Interaction between hip fracture probability, screening and falls risk

The relationship between the hazard ratio for any incident fall in the screening arm compared to that in the control arm, across the range of baseline FRAX 10-year hip fracture probabilities, is shown in Fig 2. There was no evidence of an interaction $(\mathrm{p}=0.18)$ with no difference in falls risk between the screening and control arms across the full range of baseline hip fracture probability. The results were also similar by number of incident falls (Online resource 1). Confidence intervals for the hazard ratio crossed unity at all probabilities for the various fall outcomes, with no evidence of an interaction. 
This analysis was designed to explore whether the reduction in hip fractures seen in the SCOOP study might have been mediated by a change in behaviour and decreased falls risk in the screening arm, particularly in those identified at high risk. The results show no impact of screening on the incidence of falls, however defined, and this was true across the full range of baseline fracture risk. This result complements a similar analysis which showed an interaction between screening and the reduction in hip fractures in those at higher risk in SCOOP. Together, these analyses are consistent with the effect of targeting of osteoporosis medications to such individuals[9], rather than a reduction in the frequency of falls.

Our analysis identified a number of clinical risk factors associated with a future risk of falling, consistent with existing literature [17-26], including a history of one or more falls in the previous year, a prior fracture and self-reported poor mobility. All three factors also showed a strong relationship with the occurrence of multiple falls. Interestingly, we found that FRAX hip fracture probability, calculated without input of BMD, was also predictive of future falls across all definitions of future fallers. In a study of elderly men included in the MrOS Sweden cohort, the risk of incident falls also increased with increasing FRAX probabilities at baseline[27], and our analysis suggests that this finding also applies to women.

That the reduction in hip fractures seen in SCOOP is not mediated by a change in behaviours impacting on falls risk is an important finding. While there is evidence from previous studies in other disease areas that screening can exert positive or negative influences on health behaviour [10-13], it is clear that screening for high fracture risk had no impact on falls occurrence in SCOOP. That falls risk is an important contributor to incident hip and non-vertebral fractures is both logical and demonstrable [28-32]; however, the SCOOP study demonstrates that the incidence of hip fracture can be reduced by treatments that target osteoporosis rather than falls risk. These data are in keeping with a large body of evidence from randomised, placebo-controlled clinical trials of predominantly anti-resorptive treatments in osteoporosis [6,33-35]. Of note, a similar, if smaller, reduction in hip fracture has also been reported in the ROSE screening study in Denmark using a slightly different FRAX-based strategy [36], suggesting that FRAX-based targeting of osteoporosis treatments might play a significant role in decreasing the burden of hip fractures. That the efficacy of intervention is mediated predominantly by changes in BMD is supported by the comparative effects of the intervention on hip fracture and osteoporotic fracture. For the prediction of hip fracture, risk decreases 2.6-fold for each standard deviation increase in femoral neck BMD, whereas the decrease in risk for any osteoporotic fracture is in the order of 1.5 fold[37]. Given that the hip fracture rate decreased by $28 \%$, the expected effect on osteoporotic fractures would be a hazard ratio of 0.87 ; this hazard ratio lies within the $95 \%$ confidence intervals of the effect reported in SCOOP for osteoporotic fractures $(0 \cdot 85-1 \cdot 03)$. [8] In contrast, uncertainty remains about the effectiveness and cost-effectiveness of falls prevention strategies to reduce hip fracture risk, compared, for example, to the targeted use of generic pharmacological interventions such as those used in SCOOP [4, 38-40]. This does not mean that falls prevention measures should not be included in patient management, but it does raise serious questions about the wisdom of calls for anti-osteoporosis medications for the prevention of hip fractures to be abandoned in favour of falls prevention focused strategies [41, 42].

Our study has a number of strengths and limitations. One of the strengths of this analysis was that it was undertaken within the context of a well conducted, large, randomised, controlled clinical trial with a high incidence of the outcome of interest (falls). Falls were not the primary outcome of SCOOP, however, and past falls and incident falls were captured by unverified self-report only, most commonly at one-year intervals by 
questionnaire. Self-recall is associated with lower sensitivity (under-reporting of falls) but a high specificity [43]. This recall can be influenced in studies of interventions that target falls prevention, but this was not the case in SCOOP and there is no reason to believe that any recall bias was unequally distributed between the screening and control arms. Additionally, the findings were robust across a series of definitions of fallers. Furthermore, the finding of well-established relationships between known risk factors and incident falls, however categorised, not only gives credence to the reporting of falls, but also further validates the accuracy of the observed lack of impact of screening on falls risk.

\section{Conclusion}

The SCOOP study, which targeted osteoporosis treatment to women at high risk of hip fracture, resulted in a lower incidence of hip fracture. The present analysis demonstrates that this reduction in hip fractures was not mediated by a reduction in falls risk. The additional benefits, if any, of combining effective osteoporosis treatments with approaches aimed at addressing falls risk should ideally be determined from welldesigned clinical trials to inform best clinical practice. 
1. Hernlund E, Svedbom A, Ivergard M, Compston J, Cooper C, Stenmark J, McCloskey EV, Jonsson B, Kanis JA (2013) Osteoporosis in the European Union: medical management, epidemiology and economic burden. A report prepared in collaboration with the International Osteoporosis Foundation (IOF) and the European Federation of Pharmaceutical Industry Associations (EFPIA). Arch Osteoporos 8:136

2. Cummings SR, Nevitt MC (1989) A hypothesis: the causes of hip fractures. J Gerontol 44:M107-111

3. Gillespie LD, Robertson MC, Gillespie WJ, Sherrington C, Gates S, Clemson LM, Lamb SE (2012) Interventions for preventing falls in older people living in the community. Cochrane Database Syst Rev CD007146

4. Guirguis-Blake JM, Michael YL, Perdue LA, Coppola EL, Beil TL (2018) Interventions to Prevent Falls in Older Adults: Updated Evidence Report and Systematic Review for the US Preventive Services Task Force. JAMA 319:1705-1716

5. Black DM, Cummings SR, Karpf DB, et al. (1996) Randomised trial of effect of alendronate on risk of fracture in women with existing vertebral fractures. Fracture Intervention Trial Research Group. Lancet 348:1535-1541

6. McClung MR, Geusens P, Miller PD, et al. (2001) Effect of risedronate on the risk of hip fracture in elderly women. Hip Intervention Program Study Group. N Engl J Med 344:333-340

7. Black DM, Delmas PD, Eastell R, et al. (2007) Once-yearly zoledronic acid for treatment of postmenopausal osteoporosis. N Engl J Med 356:1809-1822

8. Shepstone L, Lenaghan E, Cooper C, et al. (2018) Screening in the community to reduce fractures in older women (SCOOP): a randomised controlled trial. Lancet 391:741-747

9. McCloskey E, Johansson H, Harvey NC, et al. (2018) Management of Patients With High Baseline Hip Fracture Risk by FRAX Reduces Hip Fractures-A Post Hoc Analysis of the SCOOP Study. J Bone Miner Res 33:1020-1026

10. Deutekom M, Vansenne F, McCaffery K, Essink-Bot ML, Stronks K, Bossuyt PM (2011) The effects of screening on health behaviour: a summary of the results of randomized controlled trials. J Public Health (Oxf) 33:71-79

11. van der Aalst CM, van Klaveren RJ, de Koning HJ (2010) Does participation to screening unintentionally influence lifestyle behaviour and thus lifestyle-related morbidity? Best Pract Res Clin Gastroenterol 24:465-478

12. Bankhead CR, Brett J, Bukach C, Webster P, Stewart-Brown S, Munafo M, Austoker J (2003) The impact of screening on future health-promoting behaviours and health beliefs: a systematic review. Health Technol Assess 7:1-92

13. Larsen IK, Grotmol T, Almendingen K, Hoff G (2007) Impact of colorectal cancer screening on future lifestyle choices: a three-year randomized controlled trial. Clin Gastroenterol Hepatol 5:477-483

14. Shepstone L, Fordham R, Lenaghan E, et al. (2012) A pragmatic randomised controlled trial of the effectiveness and cost-effectiveness of screening older women for the prevention of fractures: rationale, design and methods for the SCOOP study. Osteoporos Int 23:2507-2515

15. Lamb SE, Jorstad-Stein EC, Hauer K, Becker C, Prevention of Falls Network E, Outcomes Consensus G (2005) Development of a common outcome data set for fall injury prevention trials: the Prevention of Falls Network Europe consensus. J Am Geriatr Soc 53:1618-1622

16. Kalbfleisch JD, Prentice RL (1980) statistical analysis of failure time data.

17. Callis N (2016) Falls prevention: Identification of predictive fall risk factors. Appl Nurs Res 29:53-58

18. Ambrose AF, Paul G, Hausdorff JM (2013) Risk factors for falls among older adults: a review of the literature. Maturitas 75:51-61

19. Al-Aama T (2011) Falls in the elderly: spectrum and prevention. Can Fam Physician 57:771-776

20. Geusens P, Milisen K, Dejaeger E, Boonen S (2003) Falls and fractures in postmenopausal women: a review. J Br Menopause Soc 9:101-106

21. Stenhagen M, Ekström H, Nordell E, Elmståhl S (2013) Falls in the general elderly population: a 3and 6- year prospective study of risk factors using data from the longitudinal population study 'Good ageing in Skane'. BMC Geriatr 13:81

22. Kojima G, Kendrick D, Skelton DA, Morris RW, Gawler S, Iliffe S (2015) Frailty predicts short-term incidence of future falls among British community-dwelling older people: a prospective cohort study nested within a randomised controlled trial. BMC Geriatr 15:155

23. Kwan MM, Close JC, Wong AK, Lord SR (2011) Falls incidence, risk factors, and consequences in Chinese older people: a systematic review. J Am Geriatr Soc 59:536-543

24. Mänty M, Heinonen A, Viljanen A, Pajala S, Koskenvuo M, Kaprio J, Rantanen T (2010) Self-reported preclinical mobility limitation and fall history as predictors of future falls in older women: prospective cohort study. Osteoporos Int 21:689-693 
25. Baccaro LF, Machado VeS, Costa-Paiva L, Sousa MH, Osis MJ, Pinto-Neto AM (2013) Treatment for menopausal symptoms and having health insurance were associated with a lower prevalence of falls among Brazilian women. Maturitas 75:367-372

26. Deandrea S, Lucenteforte E, Bravi F, Foschi R, La Vecchia C, Negri E (2010) Risk factors for falls in community-dwelling older people: a systematic review and meta-analysis. Epidemiology 21:658-668

27. Harvey NC, Johansson H, Oden A, et al. (2016) FRAX predicts incident falls in elderly men: findings from MrOs Sweden. Osteoporos Int 27:267-274

28. Harvey NC, Oden A, Orwoll E, et al. (2018) Falls Predict Fractures Independently of FRAX Probability: A Meta-Analysis of the Osteoporotic Fractures in Men (MrOS) Study. J Bone Miner Res 33:510516

29. Nilsson M, Eriksson J, Larsson B, Oden A, Johansson H, Lorentzon M (2016) Fall Risk Assessment Predicts Fall-Related Injury, Hip Fracture, and Head Injury in Older Adults. J Am Geriatr Soc 64:2242-2250 30. Edwards MH, Jameson K, Denison H, Harvey NC, Sayer AA, Dennison EM, Cooper C (2013) Clinical risk factors, bone density and fall history in the prediction of incident fracture among men and women. Bone 52:541-547

31. Hippisley-Cox J, Coupland C (2009) Predicting risk of osteoporotic fracture in men and women in England and Wales: prospective derivation and validation of QFractureScores. Bmj 339:b4229

32. Nguyen ND, Pongchaiyakul C, Center JR, Eisman JA, Nguyen TV (2005) Identification of high-risk individuals for hip fracture: a 14-year prospective study. J Bone Miner Res 20:1921-1928

33. Black DM, Thompson DE, Bauer DC, Ensrud K, Musliner T, Hochberg MC, Nevitt MC, Suryawanshi S, Cummings SR (2000) Fracture risk reduction with alendronate in women with osteoporosis: the Fracture Intervention Trial. FIT Research Group. J Clin Endocrinol Metab 85:4118-4124

34. Black DM, Delmas PD, Eastell R, et al. (2007) Once-yearly zoledronic acid for treatment of postmenopausal osteoporosis. N Engl J Med 356:1809-1822

35. Cummings SR, San Martin J, McClung MR, et al. (2009) Denosumab for prevention of fractures in postmenopausal women with osteoporosis. N Engl J Med 361:756-765

36. Rubin KH, Rothmann MJ, Holmberg T, et al. (2018) Effectiveness of a two-step population-based osteoporosis screening program using FRAX: the randomized Risk-stratified Osteoporosis Strategy Evaluation (ROSE) study. Osteoporos Int 29:567-578

37. Marshall D, Johnell O, Wedel H (1996) Meta-analysis of how well measures of bone mineral density predict occurrence of osteoporotic fractures. Bmj 312:1254-1259

38. El-Khoury F, Cassou B, Charles MA, Dargent-Molina P (2013) The effect of fall prevention exercise programmes on fall induced injuries in community dwelling older adults: systematic review and meta-analysis of randomised controlled trials. BMJ 347:f6234

39. Frick KD, Kung JY, Parrish JM, Narrett MJ (2010) Evaluating the cost-effectiveness of fall prevention programs that reduce fall-related hip fractures in older adults. J Am Geriatr Soc 58:136-141

40. Turner DA, Khioe RFS, Shepstone L, et al. (2018) The Cost-Effectiveness of Screening in the Community to Reduce Osteoporotic Fractures in Older Women in the UK: Economic Evaluation of the SCOOP Study. J Bone Miner Res 33:845-851

41. Jarvinen TL, Michaelsson K, Jokihaara J, et al. (2015) Overdiagnosis of bone fragility in the quest to prevent hip fracture. BMJ 350:h2088

42. Compston J (2015) Overdiagnosis of osteoporosis: fact or fallacy? Osteoporos Int 26:2051-2054

43. Mackenzie L, Byles J, D'Este C (2006) Validation of self-reported fall events in intervention studies. Clin Rehabil 20:331-339 
Figure and Table Legend

Fig. 1 Fall-free survival estimated by Kaplan-Meier analysis for the outcomes of a) any fall (i.e. one or more) and b) multiple falls defined as 10 falls or more. There were no statistically significant differences between screening and control groups. NB Note differences in the y-axis scales between the figures.

Fig. 2 Impact of screening on falls risk (defined as one fall or more during follow-up) compared to the control arm, expressed as hazard ratio, across range of FRAX 10-year hip fracture probabilities at baseline, calculated without BMD.

Table 1 Baseline characteristics of women assigned to the control and screening arms of the SCOOP study.

Table 2 Characteristics of women reporting at least one fall compared to those with no falls in the year prior to study entry.

Table 3 Table showing the number of incident falls reported by individual participants who fell at least once during follow up in the SCOOP study.

Table 4 Association between baseline variables and future falls risk, stratified by number of incident falls. Numbers represent the hazard ratio (HR) and 95\%CI for the presence of the factor, other than for continuous variables where the HR relates to a unit increase in the variable, adjusted for age and time since baseline. Numbers in bold represent HRs with a CI that excludes the null.

Table 5 Hazard ratio $(95 \% \mathrm{CI})$ between screening and control arms for various outcomes of falls at different values of FRAX 10-year probability (\%) of a hip fracture calculated without BMD. In the model, FRAX probability was a continuous variable; for illustrative purposes, the table shows the effect at various values of baseline probability. The p-value is for the interaction between screening and the outcome. 
Fig. 1 - Fall-free survival estimated by Kaplan-Meier analysis for the outcomes of a) any fall (i.e. one or more) and b) multiple falls defined as 10 falls or more. There were no statistically significant differences between screening and control groups. NB Note differences in the y-axis scales between the figures.
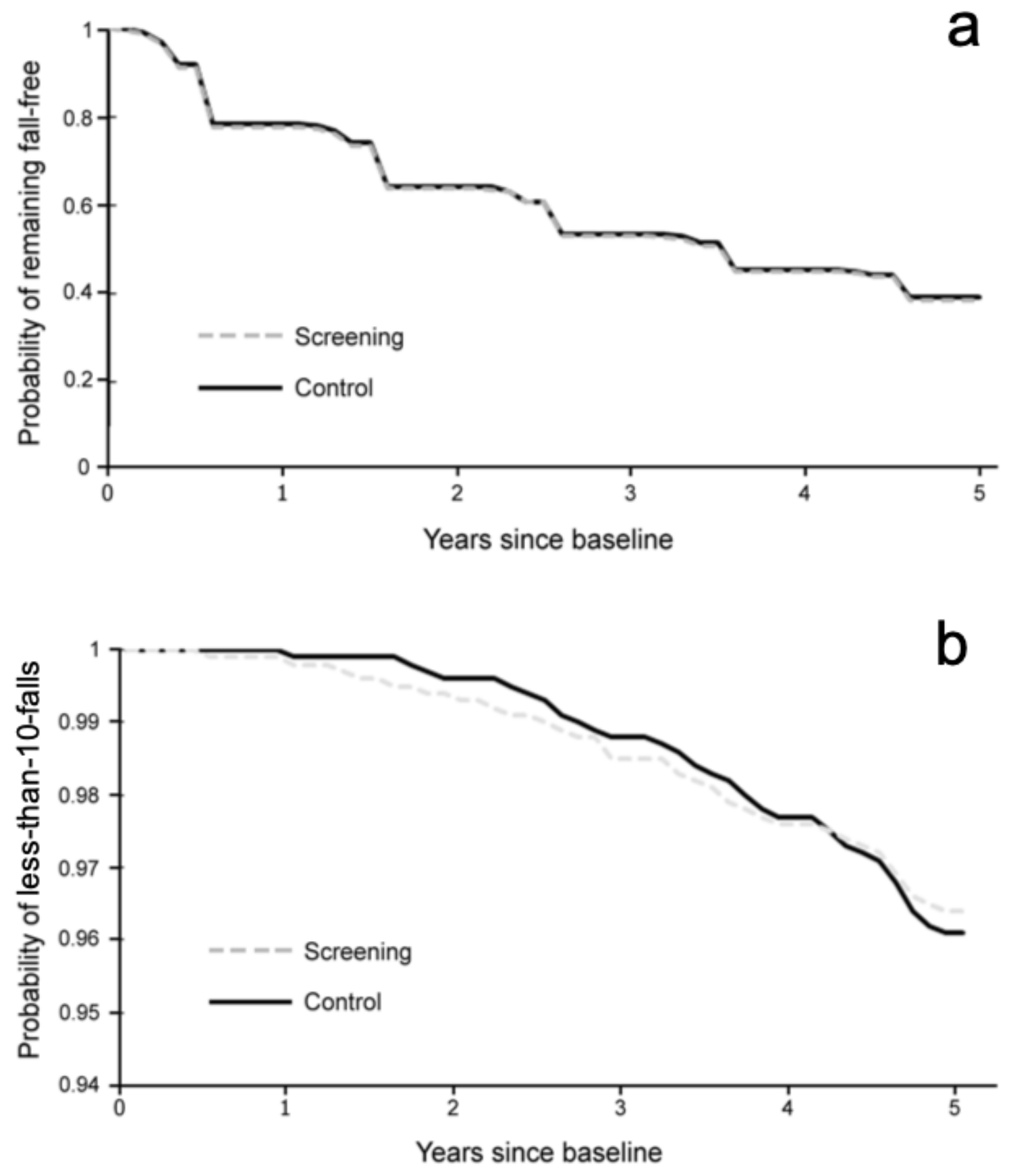
Fig. 2 Impact of screening on falls risk (defined as one fall or more during follow-up) compared to the control arm, expressed as hazard ratio, across the range of FRAX 10-year hip fracture probabilities at baseline, calculated without BMD.

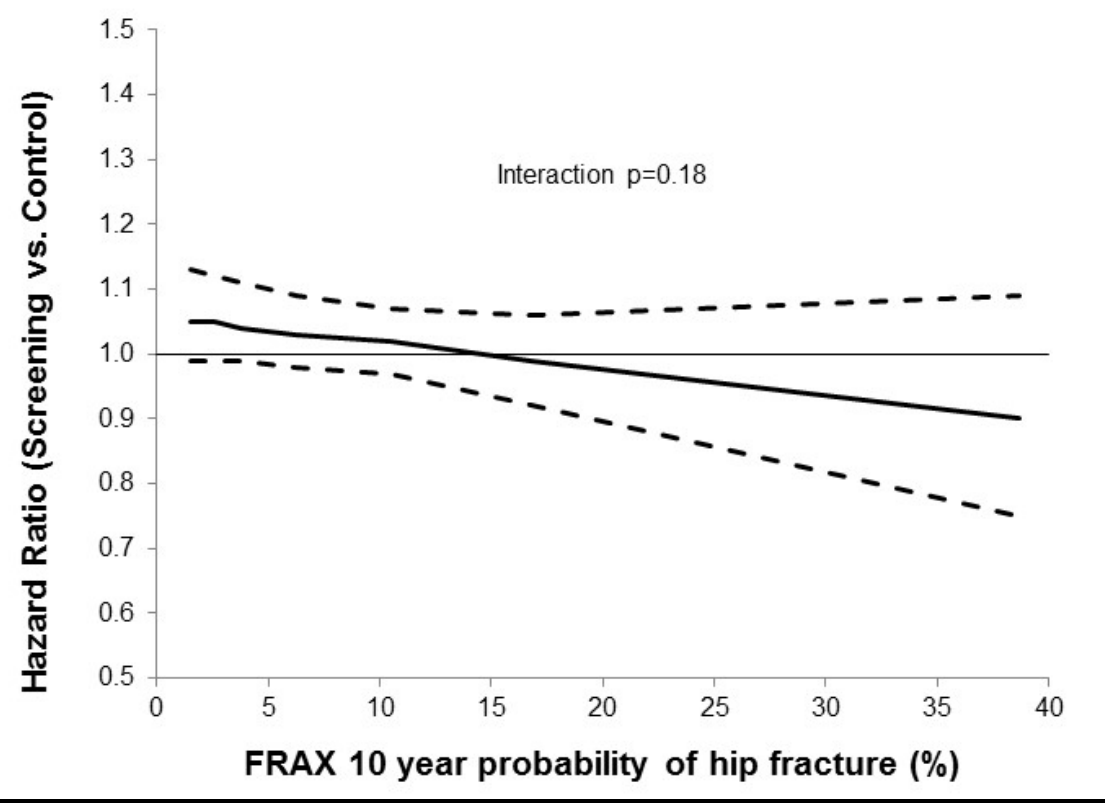


Table 1 Baseline characteristics of women assigned to the control and screening arms of the SCOOP study.

\begin{tabular}{|l|c|c|}
\hline Mean (SD) or n (\%) & $\begin{array}{c}\text { Control } \\
\text { (N=6250) }\end{array}$ & $\begin{array}{c}\text { Screening } \\
\text { (N=6233) }\end{array}$ \\
\hline Age, years & $75.5(4.1)$ & $75.4(4.2)$ \\
\hline Height, cm & $160.7(6.3)$ & $160.9(6.4)$ \\
\hline Weight, kg & $68.9(12.7)$ & $69.1(12.7)$ \\
\hline BMI, kg/m & $26.7(4.8)$ & $26.7(4.7)$ \\
\hline Self-reported prevalence (n, \%) of: & $1463(23.4)$ & $1399(22.4)$ \\
Fracture since age 50 years & $577(9.2)$ & $585(9.4)$ \\
Parental hip fracture & $290(4.6)$ & $290(4.7)$ \\
Current smoking & $225(3.6)$ & $219(3.5)$ \\
Alcohol $\geq \mathbf{3}$ units/day & $312(5.0)$ & $316(5.1)$ \\
Glucocorticoid Use & $410(6.6)$ & $426(6.8)$ \\
Rheumatoid Arthritis & $1408(22.5)$ & $1483(23.8)$ \\
Secondary Causes of OP & & \\
\hline Falls in previous 12 months: & $1744(28.0)$ & $1700(27.2)$ \\
Yes $\geq \mathbf{1}$ fall) & $895(14.3)$ & $901(14.5)$ \\
\hline Yes ( $\geq \mathbf{2}$ falls)
\end{tabular}


Table 2 Characteristics of women reporting at least one fall compared to those with no falls in the year prior to study entry.

\begin{tabular}{|c|c|c|c|}
\hline Mean (SD) or n (\%) & $\begin{array}{r}\text { No previous } \\
\text { fall }(n=8924)\end{array}$ & $\begin{array}{c}\text { Previous fall } \\
(\mathrm{n}=3444)\end{array}$ & p-value \\
\hline Age, years & $75.4(4.1)$ & $76(4.3)$ & $<0.001$ \\
\hline BMI, $\mathrm{kg} / \mathrm{m}^{2}$ & $26.5(6.3)$ & $27.1(5.0)$ & $<0.001$ \\
\hline Prior fracture (\%) & $1812(20.3)$ & $1021(29.6)$ & $<0.001$ \\
\hline Parental hip fracture (\%) & $804(9.0)$ & $348(10.1)$ & 0.007 \\
\hline Current smoking (\%) & $420(4.7)$ & $152(4.4)$ & 0.489 \\
\hline Alcohol $\geq 3$ units/day (\%) & $298(3.3)$ & $141(4.1)$ & 0.049 \\
\hline Glucocorticoid use (\%) & $421(4.7)$ & $203(5.9)$ & 0.003 \\
\hline Rheumatoid arthritis (\%) & $538(6.0)$ & $284(8.2)$ & $<0.001$ \\
\hline Secondary osteoporosis (\%)* & $1879(21.1)$ & $979(28.4)$ & $<0.001$ \\
\hline $\begin{array}{ll}\text { - Insulin-dependent diabetes } \\
\text { mellitus (\%) }\end{array}$ & $157(1.8)$ & $91(2.6)$ & 0.015 \\
\hline - Crohn's disease (\%) & $136(1.5)$ & $66(1.9)$ & $<0.001$ \\
\hline - $\quad$ Overactive thyroid (\%) & $443(5.0)$ & $199(5.8)$ & 0.041 \\
\hline - $\quad$ Early menopause (\%) & $943(10.6)$ & $462(13.4)$ & $<0.001$ \\
\hline - $\quad$ Organ transplant $(\%)$ & $32(0.4)$ & $17(0.5)$ & 0.581 \\
\hline - $\quad$ Poor mobility (\%) & $422(4.7)$ & $342(9.9)$ & $<0.001$ \\
\hline
\end{tabular}


Table 3 Table showing the number of incident falls reported by individual participants who fell at least once during follow up in the SCOOP study.

\begin{tabular}{|c|c|}
\hline $\begin{array}{c}\text { Number of reported incident } \\
\text { falls }\end{array}$ & $\mathbf{n}(\mathbf{\%})$ \\
\hline $\mathbf{1}$ & $2469(36.5)$ \\
\hline $\mathbf{2}$ & $1437(21.3)$ \\
\hline $\mathbf{3}$ & $837(12.4)$ \\
\hline $\mathbf{4}$ & $532(7.9)$ \\
\hline $\mathbf{5}$ or more & $1485(22.0)$ \\
\hline $\mathbf{1 0}$ or more & $418(6.2)$ \\
\hline
\end{tabular}


Table 4 Association between baseline variables and future falls risk, stratified by number of incident falls. Numbers represent the hazard ratio (HR) and 95\%CI for the presence of the factor, other than for continuous variables where the HR relates to a unit increase in the variable, adjusted for age and time since baseline. Numbers in bold represent HRs with a CI that excludes the null.

\begin{tabular}{|c|c|c|c|}
\hline & \multicolumn{3}{|c|}{ Incident falls } \\
\hline & $\geq 1$ fall & $\geq 5$ falls & $\geq 10$ falls \\
\hline BMI $\left(1 \mathrm{~kg} / \mathrm{m}^{2}\right.$ increase $)$ & $1.01(1.01,1.02)$ & $1.04(1.03,1.05)$ & $1.07(1.05,1.09)$ \\
\hline Prior fracture & $1.21(1.15,1.28)$ & $1.35(1.20,1.51)$ & $1.54(1.24,1.91)$ \\
\hline Parental hip fracture & $1.19(1.09,1.29)$ & $1.13(0.94,1.34)$ & $0.97(0.68,1.39)$ \\
\hline Current smoking & $0.92(0.81,1.04)$ & $1.13(0.87,1.46)$ & $1.55(1.01,2.38)$ \\
\hline Alcohol $\geq 3$ units/day & $1.03(0.91,1.17)$ & $1.10(0.84,1.44)$ & $0.74(0.40,1.40)$ \\
\hline Glucocorticoid use & $1.24(1.12,1.38)$ & $1.55(1.26,1.90)$ & $1.65(1.13,2.42)$ \\
\hline Rheumatoid arthritis & $1.16(1.05,1.27)$ & $1.50(1.24,1.80)$ & $1.34(0.93,1.93)$ \\
\hline Secondary osteoporosis & $1.31(1.24,1.38)$ & $1.76(1.58,1.97)$ & $2.80(2.29,3.42)$ \\
\hline $\begin{array}{l}\text { Insulin-dependent } \\
\text { diabetes mellitus }\end{array}$ & $1.22(1.03,1.45)$ & $1.71(1.25,2.34)$ & $2.88(1.79,4.62)$ \\
\hline - Crohn's disease & $1.15(0.96,1.39)$ & $1.45(1.01,2.07)$ & $1.67(0.89,3.12)$ \\
\hline - $\quad$ Overactive thyroid & $1.07(0.96,1.19)$ & $1.24(0.99,1.54)$ & $1.74(1.20,2.51)$ \\
\hline - $\quad$ Early menopause & $1.20(1.12,1.29)$ & $1.31(1.13,1.53)$ & $1.45(1.10,1.92)$ \\
\hline - Organ transplant & $1.51(1.06,2.15)$ & $1.88(0.98,3.62)$ & $2.98(1.11,7.98)$ \\
\hline - $\quad$ Poor mobility & $1.75(1.59,1.92)$ & $3.35(2.88,3.89)$ & $6.20(4.90,7.83)$ \\
\hline $\begin{array}{l}\text { Fall in previous year ( } \geq 1 \text { fall, yes } \\
\text { or no) }\end{array}$ & $2.03(1.93,2.14)$ & $3.84(3.46,4.27)$ & $6.38(5.13,7.94)$ \\
\hline $\begin{array}{l}\text { Fall in previous year (increase } \\
\text { per reported fall) }\end{array}$ & $1.10(1.09,1.11)$ & $1.14(1.13,1.15)$ & $1.15(1.14,1.16)$ \\
\hline $\begin{array}{l}\text { FRAX 10y hip probability (1\% } \\
\text { increase) }\end{array}$ & $1.01(1.01,1.01)$ & $1.01(1.01,1.02)$ & $1.02(1.00,1.03)$ \\
\hline Screening & $1.02(0.98,1.07)$ & $0.99(0.89,1.10)$ & $0.94(0.77,1.15)$ \\
\hline
\end{tabular}


Online resource 2- Further analysis for evaluate an impact of antiosteoporosis treatment to falls risk per screening or control group

\begin{tabular}{|c|c|c|c|c|}
\hline & & $\geq 1$ fall & $\geq 5$ falls & $\geq 10$ falls \\
\hline \multicolumn{5}{|l|}{ Anti-osteoporosis treatment } \\
\hline \multirow[t]{2}{*}{ - Within 5 months } & Control & $1.20(0.96,1.49)$ & $1.08(0.67,1.74)$ & $1.15(0.47,2.80)$ \\
\hline & Screening & $1.12(1.01,1.23)$ & $0.96(0.77,1.20)$ & $0.90(0.58,1.40)$ \\
\hline \multirow[t]{2}{*}{ - Within 1 years } & Control & $1.34(1.12,1.55)$ & $1.30(0.93,1.81)$ & $1.83(1.07,3.16)$ \\
\hline & Screening & $1.19(1.09,1.31)$ & $1.09(0.89,1.33)$ & $1.14(0.77,1.67)$ \\
\hline \multirow{2}{*}{$\begin{array}{ll} & \text { At sometimes } \\
\text { during follow up }\end{array}$} & Control & $1.58(1.45,1.72)$ & $1.51(1.26,1.80)$ & $1.97(1.43,2.70)$ \\
\hline & Screening & $1.33(1.23,1.44)$ & $1.24(1.05,1.47)$ & $1.25(0.91,1.72)$ \\
\hline
\end{tabular}

